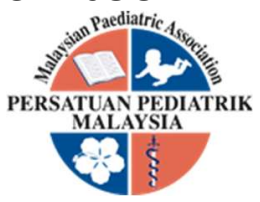

\title{
BURNOUT AND STRESSOR-RELATED FACTORS AMONG CARETAKER OF CHILDREN WITH CHRONIC NEUROLOGICAL ILLNESS
}

\author{
Siti Ai'syah Abdullah',2, Salmi Ab Razak', Muhammad Saiful Bahri Yusoff ${ }^{1}$, Azizah Othman ${ }^{1}$, Nor Azni \\ Yahaya $^{2}$, Norsarwany Mohamad'
}

\begin{abstract}
Objective: Caring for children with neurological conditions is challenging. This study aimed to determine the prevalence of burnout and its associated factors among caretakers of children with chronic neurological illness. Method: This cross-sectional study involved 18 years or older caretakers of children with neurological illness for more than 3 months duration. They were recruited from Paediatric Neurology outpatient clinics over a period of 3 months from July to October 2019 at a general hospital in the state of Kelantan, Malaysia. Each caretaker was given a set of questionnaires that included General Stressor Questionnaire (GSQ) which was translated into Malay version 'Soal Selidik Umum (SSU)', Copenhagen Burnout Inventory-Malay version (CBI-M) and Demographic Information Form. Results: Overall, only 20 caretakers had mean score of 50 or higher in all component in CBI-M, making the prevalence of total burnout among the caretakers of $8.3 \%(95 \% \mathrm{Cl}=5.2 \%, 12.6 \%)$. Personal burnout involved 78 caretakers $(32.5 \%, 95 \% \mathrm{Cl}=26.6 \%, 38.8 \%), 42$ caretakers with client-related burnout $(17.5 \%, 95 \% \mathrm{Cl}=12.9 \%, 22.9 \%)$ and 11 caretakers had work-related burnout $(4.6 \%, 95 \% \mathrm{Cl}=2.3 \%, 8.1 \%)$. Most common stressors were performance pressure, work-family conflict and poor job prospects. Multiple logistic regression analyses showed that family stressors, types of children's neurological illness and number of household occupants were associated with personal burnout, client-related burnout and total burnout in their caretakers. Conclusions: Prevalence of total burnout among the caretakers was low, but personal burnout was prominent. Caretakers of children with genetic illness, cerebral palsy and autism had higher prevalence of burnout compared to other chronic neurological illness.
\end{abstract}

Keywords: Burnout, Stressor, Caretaker, Children, chronic neurological illness

DOI: $10.51407 /$ mjpch.v27i2.140

\section{Introduction}

Caring for children is a wonderful and rewarding experience. However, parents may be exposed to stress attempting to meet the challenges of caring for their own child. This is more profound in those caring for children with chronic neurological illness [1]. Burnout is originally described as a psychological syndrome emerging as a prolonged response to chronic stressors related to the workplace environment. Key dimensions are overwhelming exhaustion, feelings of cynicism and detachment from the
Received: 22 December 2020; Accepted revised manuscript: 15 June 2021

Published online: 24 August 2021

job, and a sense of ineffectiveness and lack of accomplishment [2].

The associations between physical and psychological health, and being an informal

\footnotetext{
1. Department of Paediatrics, School of Medical Sciences, Universiti Sains Malaysia, 16150, Kubang Kerian, Kelantan, Malaysia

2. Department of Paediatrics, Hospital Raja Perempuan Zainab II, Kota Bharu, Kelantan, Malaysia

3. Department of Medical Education, School of Medical Sciences, Universiti Sains Malaysia, 16150, Kubang Kerian, Malaysia Corresponding Author:

Assoc. Prof. Dr Norsarwany Mohamad, Department of Paediatrics, School of Medical Sciences, Universiti Sains Malaysia, 16150, Kubang Kerian, Kelantan, Malaysia. Tel.: +6097676540 Email: sarwany@usm.my
} 
caregiver are well established [3]. Caring for children with chronic neurological illness may imposed higher burden physically and emotionally [1]. The act of caring might be accompanied by high levels of unpredictability and uncontrollability. As a consequence these factors may create secondary stress in multiple life domains, requiring high levels of vigilance and coping styles [1].

Burnout is a specific syndrome of exhaustion related to prolonged emotional imbalance, where the burden of perceived stress is overwhelming and exceeds coping strategies [4]. Burnout concept was first described in the mid-1970s as a syndrome specifically related to working environment, regarded as occupational hazard [2]. Recent studies showed evidence of exhaustion not only at the workplace, but also as a result of being a parent $[5,6]$. Parental burnout is characterized by physical and emotional exhaustion, emotional distancing from one's child, and a sense of incompetency in parenting roles [7]. However, parental stress does not always lead to parental burnout [8].

Parental suffering in relation to children chronic illness is likely to occur at 3 main points. Prior to diagnosis, the family need to battle with disruption to ideal family life with child's recurrent ill health. Secondly, parents will experience a reaction to diagnosis of the condition, which may include complex feelings of loss, guilt, fear and even shame. In the end, parents may suffer in relation to period of adjustment, including challenges of disease management and supporting their child [9].

Caretakers may need to provide wide variety of assistance for their children [3]. Although care giving can be profoundly fulfilling, it can also cause physical and psychological disturbances $[10,11]$. Caretakers of children with neurological illness such as cerebral palsy need to overcome the extra burden in dealing with their children's impairment or disabilities [11]. Children with disabilities are more likely to reside with caregivers with high levels of financial and psychological stress [12]. Burnout symptoms are more common to parents of children with chronic diseases as compared to those with normal children [13]. Parental burnout has larger associations with couple's conflict, escape and suicidal ideation, child neglect and parental violence [7].

Many studies have been conducted internationally and locally to identify burnout in the medical workforce and formal caregivers. However, local data regarding burnout in caretakers of children with chronic illness are lacking. A local study found that $52 \%$ of mothers of children with developmental disabilities experienced psychological health problems with the highest prevalence exhibited by mothers of children with intellectual disability, autism and Down syndrome [14]. Another study in parents of children with Down Syndrome showed mean parenting stress was significantly higher among children with reported behavioral problems compared to others [15]. Recently the Copenhagen Burnout Inventory (CBI) was translated and validated into Malay version, $\mathrm{CBI}$ $M$ [16]. This provides an opportunity to study burnout in caretakers among the Malaysian population, using the Malay language as their first language.

The main objective of the study was to describe prevalence of burnout in caretakers of children with chronic neurological illness by utilizing Copenhagen Burnout Inventory-Malay version (CBI-M). It also investigated possible stressors among these caretakers as well as other sociodemographic factors associated with burnout.

\section{Methods}

\section{Study design and participants}

This was a cross-sectional study, recruiting caretakers from Paediatric Neurology Clinic over a period of three months. It was conducted in Hospital Raja Perempuan Zainab II, a tertiary hospital in the state of Kelantan, Malaysia. This study was approved by Medical Research and Ethics Committee, National Medical Research Register, Ministry of Health, Malaysia (NMRR-183689-45251) as well as The Human Research Ethics Committee of Universiti Sains Malaysia (Ethical approval code USM/JEPEM/19030191). This study was a part of Universiti Sains Malaysia Research University Grant.

Caretakers including parents or guardian of children aged less than 18 years old with chronic neurological illness were recruited via convenient sampling over a 3-month period from July 2019 to October 2019. Participants were approached 
by principal investigator/trained research assistant during their children's regular scheduled follow-up at neurology outpatient clinic. Subjects were allowed sufficient time to consider their participation in the study. Written informed consent was obtained. Guided questionnaires including Copenhagen Burnout Inventory and General Stressors Questionnaires were used to identify burnout and associated stressors. Inclusion criteria were the main caretaker of children who were attending neurology clinic and the caretaker must be 18 years or older, caring for children with chronic neurological condition including cerebral palsy, attention-deficit hyperactive disorder (ADHD), autism, epilepsy and developmental delay for the duration of more than 3 months. The children under care were aged between 3 months to 18 years old. Exclusion criteria were caretakers who were not proficient in Malay language and did not give informed consent.

Sample size calculation was based on $95 \%$ confidence interval with power of study $80 \%$. The main objective to determine the prevalence of burnout was used in the single proportion formula [17]. Prevalence of burnout of $56 \%$ was derived from a study looking at prevalence of psychological problems among caretakers of children with cerebral palsy [3]. Considering 20\% non-response rate, the minimum required sample for caretakers was 232 .

\section{Research tools}

Two validated questionnaires were used, which were General Stressor Questionnaire (GSQ) and CBI-M. GSQ was translated and validated into Malay language as "Soal Selidik Umum" (SSU) [18]. This Malay language version, SSU was used to identify common stressor among caregiver of children with chronic neurological condition. It comprised of 28 items with 7 domains (Family, Performance Pressure, Work-Family Conflicts, Bureaucratic Constraints, Poor Relationship with Superior, Poor Relationship with Colleagues and Poor Job Prospect). Each domain consisted of 4 questions. Each question used Likert-score 0 to 4 (0-causing no stress, 1-mild stress, 2-moderate stress, 3-high stress, 4-severe stress).

Family related stressors described as events occurring in family that can lead to person's emotional disturbances such as poor relationship with the spouse, poor support from family members and having lack of skill in managing family $[18,19]$. Performance pressure related stressors described as work demands that cause emotional disturbances to a person such as work overload, where any mistake can lead to disastrous consequences [18]. Work-family conflicts related stressors described as work events that compromise a person's personal and home life that lead to distress feelings such as advancing career at the expense of personal or home life $[18,20]$. Bureaucratic constraints related stressors was described as organizational working environment that can cause distress feeling to a person such as lack of support from authority [18]. A poor relationship with the superior and colleagues related stressors described as interpersonal relationship events that can cause distress feelings to a person such as lack of support from superior and uncooperative colleagues [18]. The job prospect related stressors described as events related to reward and recognition such as feeling of being underpaid and lack of recognition to the job [18].

CBI-M were used for study of burnout in caretakers. It comprised of 3 sub-dimensions including personal burnout, work-related burnout, and client-related burnout. Personal burnout referred to degree of physical and psychological fatigue and exhaustion experienced by the person [21]. Work-related burnout referred to degree of physical and psychological fatigue and exhaustion that was perceived by the person as related to his or her work [21]. Client-related burnout referred to degree of physical and psychological fatigue and exhaustion that was perceived by the person as related to his or her work with their child [21].

Both tools were previously used in different populations. Burnout was previously well recognized as work-related entity [22]. At the beginning of this study, there were no standard tools available for measuring parental burnout. Thus, the CBI-M (validated tool for job burnout) was adapted into the current sample of caretakers, whereby caretakers were asked to consider taking care of their children as 'work'. The current study aimed at identifying burnout and stressor-related factors in caretakers of children with chronic neurological illness, including housewives and fathers who were 
unemployed. Both tools were previously utilized in another study involving 78 caretakers of children with cancer, receiving treatment in Hospital Universiti Sains Malaysia in 2019. Overall reliability data was calculated with Cronbach's alpha for CBI-M and GSQ were 0.89 and 0.96, respectively [23].

\section{Statistical analysis}

Diseases were grouped into several subcategories to facilitate data analysis including epilepsy, cerebral palsy, autism, attention-deficit hyperactive disorder, developmental delay, intellectual disability, genetic, metabolic and acquired neurological disorder. Genetic disorder included the neurological condition associated with gene abnormality, including Neurofibromatosis, Tuberous sclerosis, Joubert Syndrome and Dandy-Walker Malformation. Metabolic disorder was referring to neurological condition associated with metabolic disturbances including neurotransmitter disease, myasthenia, and mitochondrial myopathy, encephalopathy, lactic acidosis, and stroke (MELAS). Acquired neurological disorder were those not due to congenital malformation or genetic disorder and developed after birth following infection or trauma and contributed to neurological sequelae, including meningitis, encephalitis and acute disseminated encephalomyelitis (ADEM).

Data was entered and analysed using IBM SPSS version 24. Descriptive statistics were used to summarise socio-demographic characteristics of participants. Numerical data were presented as mean (SD). Categorical data was presented as frequency. Mean of total scores for each subdimensions of CBI-m calculated with scores of 50 or more considered as significant [21]. Scores were calculated according to specific domains in SSU. Final mean score of 2 or more was considered as significant stressors in the current study [18]. Factors associated with burnout were analysed using simple logistic regression and multiple logistic regressions. Dependent variables included personal burnout, work-related burnout and client-related burnout.

\section{Results}

The children's caretakers were identified and screened for eligibility during a 3 months period.
Two hundred and forty-five caretakers agreed to participate in the study. However, only 240 caretakers $(98.0 \%)$ were analysed. The reasons for exclusion were missing data (4 caretakers, $1.6 \%$ ) and patient over 18 years old (1 caretaker, $0.4 \%$ ). Most of the caretakers were staying in Kota Bharu (43.3\%). Majority of them were female $(82.1 \%)$, Malay $(94.6 \%)$ and Muslim (95.8\%). Most of the participant owned their house $(79.3 \%)$, had 3 rooms in the house (39.7\%) and had total 5 occupants in their house (23.4\%).

Most caretakers were high school graduates (47.7\%), working full time $(60.0 \%)$ and most were working in government sectors (51.0\%). Thirtyseven percent of caretakers were housewives. Mean working-hour for those working full time was 8.08 hours $(S D=1.85)$ while for those working part-time was 6.50 hours (SD $=1.29$ ). Those working in government sectors had mean working hour of 8.14 hours (SD $=1.13$ ), while mean working hour for private sectors was 8.39 hours (SD = 1.91) and mean working hour for selfemployed caretakers was 7.61 hours (SD $=2.63$ ). Those working full time had higher median of salary with median of RM 2,000 (IQR =2,900) as compared to those working part-time with median salary of RM 1,200 (IQR = 1,925). Those working in government sectors had the highest median salary with median salary of RM 3,000 (IQR $=2,861)$, as compared to private sectors with median salary of RM $1,400(I Q R=1,175)$ and selfemployed with median salary of RM 1,000 $(\mathrm{IQR}=1,300)$.

Mean age of children with chronic neurological illness in this study was 7.19 years old $(S D=4.21)$, and most of them were male (60.8\%) and already had the illness for more than 5 years (38.3\%). Details were listed in Table 1. 
Table 1: Demographic data of children with chronic neurological illness, $(n=240)$

\begin{tabular}{lll}
\hline Patient's Demographic & & $\mathrm{n}(\%)$ \\
\hline Age (year) & & $7.19(4.21)^{\mathrm{a}}$ \\
Gender & Male & $146(60.8)$ \\
& Female & $94(39.2)$ \\
Types of Illness & Acquired neurological disorder & $6(2.5)$ \\
& ADHD & $8(3.3)$ \\
& Autism & $24(10.0)$ \\
& Cerebral Palsy & $62(25.8)$ \\
& Developmental Delay & $53(22.1)$ \\
& Epilepsy & $69(28.8)$ \\
& Genetic disorder & $10(4.2)$ \\
& Intellectual disability & $5(2.1)$ \\
& Metabolic disorder & $3(1.3)$ \\
Duration of IIIness & less than 1 year & $17(7.1)$ \\
& 1 to 2 years & $66(27.5)$ \\
& 3 to 4 years & $65(27.1)$ \\
& more than 5 years & $92(38.3)$ \\
& & $128(53.3)$ \\
Disability Registration & Yes & $112(46.7)$ \\
& No &
\end{tabular}

${ }^{a}$ Mean (Standard Deviation)

From 240 caretakers included in the study, only 20 caretakers had mean score of 50 or higher in all components in $\mathrm{CBI}$, making the prevalence of total burnout among the caretakers of $8.3 \%$ (95\% $\mathrm{Cl}=5.2 \%, 12.6 \%)$. The prevalence of burnout differed for each specific domain. A total of 78 caretakers had personal burnout $(32.5 \%, 95 \% \mathrm{Cl}=$ $26.6 \%, 38.8 \%), 42$ had client-related burnout $(17.5 \%, 95 \% \mathrm{Cl}=12.9 \%, 22.9 \%)$ and 11 had work- related burnout $(4.6 \%, 95 \% \mathrm{Cl}=2.3 \%, 8.1 \%)$. Out of 240 caretakers, 34 had combination of personal and client-related burnout $(14.2 \%, 95 \% \mathrm{Cl}=$ $10.0 \%, 19.2 \%), 9$ had personal and work-related burnout $(3.8 \%, 95 \% \mathrm{Cl}=1.7 \%, 7 \%)$, and 9 had both work-related and client-related burnout (3.8\%, 95\% Cl $=1.7 \%, 7 \%)$. (Table 2 ) 
Table 2: Prevalence of burnout among caretakers of children with chronic neurological illness $(n=240)$

\begin{tabular}{lcl}
\hline Burnout Subdomain* & Number of caretakers & Prevalence $(95 \% \mathrm{Cl})$ \\
\hline $\begin{array}{c}\text { Personal Burnout } \\
\text { Yes (Mean Score } \geq 50)\end{array}$ & 78 & $32.5 \%(26.6 \%, 38.8 \%)$ \\
No (Mean Score < 50) & 162 & $67.5 \%(61.2 \%, 73.4 \%)$ \\
Work Burnout & & \\
Yes (Mean Score $\geq 50)$ & 11 & $4.6 \%(2.3 \%, 8.1 \%)$ \\
No (Mean Score < 50) & 229 & $95.4(91.9,97.7 \%)$ \\
& & \\
Client Burnout & 42 & $17.5 \%(12.9 \%, 22.9 \%)$ \\
Yes (Mean Score $\geq 50)$ & 198 & $82.5 \%(77.1 \%, 87.1 \%)$ \\
No (Mean Score $<50)$ & & \\
Total Burnout* & 20 & $8.3 \%(5.2 \%, 12.6 \%)$ \\
Yes (Mean Score $\geq 50)$ & 220 & $91.7 \%(87.4 \%, 94.8 \%)$ \\
No (Mean Score < 50) & & \\
\hline
\end{tabular}

* Burnout $=$ mean score for component in each specific subdomain $\geq 50$

Total Burnout $=$ mean score for all component $\geq 50$

The prevalence of personal burnout among the caretakers of children with genetic illness was $60.0 \%(95 \% \mathrm{Cl}=26.2 \%, 87.8 \%)$, followed by cerebral palsy $(43.5 \%, 95 \% \mathrm{Cl}=31.0 \%, 56.7 \%)$ and autism $(37.5 \%, 95 \% \mathrm{Cl}=18.8 \%, 59.4 \%)$. The highest prevalence of client-related burnout was among the caretakers of children with genetic illness $(30.0 \%, 95 \% \mathrm{Cl}=6.7 \%, 65.2 \%)$, followed by autism $(29.2 \%, 95 \% \mathrm{Cl}=12.6 \%, 51.1 \%)$ and cerebral palsy $(27.4 \%, 95 \% \mathrm{Cl}=16.9 \%, 40.2 \%)$. The highest prevalence of work burnout was among the caretakers of children with metabolic illness $(33.3 \%, 95 \% \mathrm{Cl}=0.8 \%, 90.6 \%)$, followed by intellectual disability $(20.0 \%, 95 \% \mathrm{Cl}=0.5 \%$, $71.6 \%)$ and autism $(12.5 \%, 95 \% \mathrm{Cl}=2.7 \%, 32.4 \%)$. The highest prevalence of total burnout was among the caretakers of children with genetic illness $(30.0 \%, 95 \% \mathrm{Cl}=6.7 \%, 65.2 \%)$, followed by intellectual disability $(20.0 \%, 95 \% \mathrm{Cl}=0.5 \%$, $71.6 \%)$ and autism $(16.7 \%, 95 \% \mathrm{Cl}=4.7 \%, 37.4 \%)$. Most common stressors were performance pressure stressor $(11.3 \%)$, work-family conflict stressor (6.7\%) and poor job prospect stressor (5.8\%).

Univariable analysis with simple logistic regression show that number of house occupant, type of illness, registration for people with disability with Welfare Department, number of siblings, family stressor, poor relationship with superior stressor, bureaucratic constraints stressor, work-family conflict stressor, performance pressure stressor and poor job prospect pressure stressor had significant association with personal burnout. Multiple logistic regression analyses showed that when adjusted to caretaker's gender, number of house occupant, type of the children's illness, family stressor, performance pressure stressor and poor job prospect stressor, it was found that all the variables had significant association with personal burnout among caretakers of children with chronic neurological illness (Table 3). 
Table 3: Factors associated with personal burnout among caretakers of children with chronic neurological illness $(n=240)$

\begin{tabular}{|c|c|c|c|c|c|c|c|}
\hline \multirow[t]{2}{*}{ Variable } & & \multicolumn{3}{|c|}{ Simple Logistic Regression } & \multicolumn{3}{|c|}{ Multiple Logistic Regression } \\
\hline & & $\begin{array}{l}\text { Crude } \\
\beta\end{array}$ & $\begin{array}{l}\text { Crude OR (95\% } \\
\text { Cl) }\end{array}$ & $\begin{array}{l}\mathrm{p}- \\
\text { value }\end{array}$ & $\begin{array}{l}\text { Adj. } \\
\beta\end{array}$ & $\begin{array}{l}\text { Adj. OR (95\% } \\
\text { Cl) }\end{array}$ & $\begin{array}{l}\mathrm{p}- \\
\text { value }\end{array}$ \\
\hline Caretaker's Age & 30 and below & 0 & 1 & & & & \\
\hline \multirow[t]{4}{*}{ (years) } & $31-35$ & -0.47 & $0.63(0.27,1.47)$ & 0.284 & & & \\
\hline & $36-40$ & -0.26 & $0.86(0.37,1.96)$ & 0.710 & & & \\
\hline & $41-45$ & -0.47 & $0.62(0.25,1.55)$ & 0.309 & & & \\
\hline & 46 and above & -0.83 & $0.44(0.17,1.13)$ & 0.087 & & & \\
\hline \multirow{2}{*}{$\begin{array}{l}\text { Caretaker's } \\
\text { Gender }\end{array}$} & Male & 0 & 1 & & & 1 & \\
\hline & Female & 0.71 & $2.04(0.92,4.49)$ & 0.078 & 0.94 & $\begin{array}{l}2.55(1.01 \\
6.47)\end{array}$ & 0.049 \\
\hline \multirow[t]{3}{*}{ No of occupant } & $\begin{array}{l}4 \text { occupants or } \\
\text { less }\end{array}$ & 0 & 1 & & 0 & 1 & \\
\hline & 5 or 6 occupants & 0.91 & $2.48(1.23,5.00)$ & 0.011 & 1.42 & $\begin{array}{l}4.15 \text { (1.77, } \\
9.72)\end{array}$ & 0.001 \\
\hline & $\begin{array}{l}7 \text { or more } \\
\text { occupants }\end{array}$ & 0.50 & $1.66(0.78,3.53)$ & 0.191 & 0.76 & $\begin{array}{l}2.13(0.87 \\
5.23)\end{array}$ & 0.100 \\
\hline \multirow{2}{*}{$\begin{array}{l}\text { OKU } \\
\text { Registration }\end{array}$} & No & 0 & 1 & & & & \\
\hline & Yes & 0.57 & $1.78(1.02,3.09)$ & 0.042 & & & \\
\hline \multirow[t]{9}{*}{ Type of IIIness } & Epilepsy & 0 & 1 & & 0 & 1 & \\
\hline & Metabolic & $\begin{array}{l}- \\
20.01\end{array}$ & - & 0.999 & $\begin{array}{l}- \\
20.37\end{array}$ & - & 0.999 \\
\hline & Acquired & -0.41 & $0.66(0.07,6.09)$ & 0.716 & $\begin{array}{l}- \\
0.08\end{array}$ & $\begin{array}{l}0.92(0.09 \\
9.36)\end{array}$ & 0.944 \\
\hline & Dev. Delay & 0.36 & $1.43(0.64,3.22)$ & 0.385 & 0.68 & $\begin{array}{l}1.97(0.80 \\
4.89)\end{array}$ & 0.142 \\
\hline & ADHD & 0.10 & $1.10(0.20,6.02)$ & 0.909 & 0.04 & $\begin{array}{l}1.05(0.13 \\
8.71)\end{array}$ & 0.967 \\
\hline & ID & -0.19 & $0.83(0.09 .7 .95)$ & 0.870 & $\begin{array}{l}- \\
1.37\end{array}$ & $\begin{array}{l}0.26(0.01, \\
5.61)\end{array}$ & 0.386 \\
\hline & Cerebral Palsy & 0.94 & $2.56(1.21,5.42)$ & 0.014 & 1.06 & $\begin{array}{l}2.89(1.25, \\
6.68)\end{array}$ & 0.013 \\
\hline & Autism & 0.69 & $1.99(0.73,5.39)$ & 0.177 & 0.23 & $\begin{array}{l}1.26(0.34 \\
4.59)\end{array}$ & 0.728 \\
\hline & Genetic & 1.61 & $4.97(1.25,19.81)$ & 0.023 & 1.94 & $\begin{array}{l}6.96(1.42, \\
34.03)\end{array}$ & 0.017 \\
\hline \multirow[t]{5}{*}{ No of siblings } & 1 sibling & 0 & 1 & & & & \\
\hline & 2 siblings & 1.01 & $2.74(0.97,7.77)$ & 0.057 & & & \\
\hline & 3 siblings & 1.42 & $4.13(1.49,11.47)$ & 0.007 & & & \\
\hline & 4 siblings & 1.05 & $2.86(0.98,8.36)$ & 0.055 & & & \\
\hline & $\begin{array}{l}5 \text { siblings or } \\
\text { more }\end{array}$ & 0.80 & $2.22(0.77,6.41)$ & 0.140 & & & \\
\hline
\end{tabular}


Table 3, continued.

\begin{tabular}{|c|c|c|c|c|c|c|c|}
\hline \multirow[t]{2}{*}{ Variable } & & \multicolumn{3}{|c|}{ Simple Logistic Regression } & \multicolumn{3}{|c|}{ Multiple Logistic Regression } \\
\hline & & $\begin{array}{l}\text { Crude } \\
\beta\end{array}$ & $\begin{array}{l}\text { Crude OR }(95 \% \\
\text { Cl) }\end{array}$ & $\begin{array}{l}p \text { - } \\
\text { value }\end{array}$ & $\begin{array}{l}\text { Adj. } \\
\beta\end{array}$ & $\begin{array}{l}\text { Adj. OR (95\% } \\
\mathrm{Cl})\end{array}$ & $\begin{array}{l}\mathrm{p}- \\
\text { value }\end{array}$ \\
\hline \multirow[t]{2}{*}{ Family } & $\begin{array}{l}\text { Not } \\
\text { significant }\end{array}$ & 0 & 1 & & 0 & 1 & \\
\hline & $\begin{array}{l}\text { Significant } \\
\text { Stressor }\end{array}$ & 3.27 & $\begin{array}{l}26.43(3.35 \\
208.82)\end{array}$ & 0.002 & 3.22 & $\begin{array}{l}24.94(2.46, \\
253.15)\end{array}$ & 0.007 \\
\hline \multirow[t]{2}{*}{$\begin{array}{l}\text { Poor relationship with } \\
\text { superior }\end{array}$} & $\begin{array}{l}\text { Not } \\
\text { significant }\end{array}$ & 0 & 1 & & & & \\
\hline & $\begin{array}{l}\text { Significant } \\
\text { Stressor }\end{array}$ & 1.46 & $\begin{array}{l}4.42(1.07 \\
18.16)\end{array}$ & 0.039 & & & \\
\hline \multirow[t]{2}{*}{ Bureaucratic constraints } & $\begin{array}{l}\text { Not } \\
\text { significant }\end{array}$ & 0 & 1 & & & & \\
\hline & $\begin{array}{l}\text { Significant } \\
\text { Stressor }\end{array}$ & 1.80 & $\begin{array}{l}6.06(1.56, \\
23.51)\end{array}$ & 0.009 & & & \\
\hline \multirow[t]{2}{*}{ Work-family conflicts } & $\begin{array}{l}\text { Not } \\
\text { significant }\end{array}$ & 0 & 1 & & & & \\
\hline & $\begin{array}{l}\text { Significant } \\
\text { Stressor }\end{array}$ & 1.64 & $\begin{array}{l}5.16(1.72, \\
15.41)\end{array}$ & 0.003 & & & \\
\hline \multirow[t]{2}{*}{$\begin{array}{l}\text { Poor relationship with } \\
\text { colleagues }\end{array}$} & $\begin{array}{l}\text { Not } \\
\text { significant }\end{array}$ & 0 & 1 & & & & \\
\hline & $\begin{array}{l}\text { Significant } \\
\text { Stressor }\end{array}$ & 1.86 & $\begin{array}{l}6.44(0.66 \\
62.94)\end{array}$ & 0.109 & & & \\
\hline \multirow[t]{2}{*}{ Performance pressure } & $\begin{array}{l}\text { Not } \\
\text { significant }\end{array}$ & 0 & 1 & & 0 & 1 & \\
\hline & $\begin{array}{l}\text { Significant } \\
\text { Stressor }\end{array}$ & 1.63 & $\begin{array}{l}5.10(2.17, \\
11.98)\end{array}$ & $\begin{array}{l}< \\
0.001\end{array}$ & 1.39 & $\begin{array}{l}4.02(1.41 \\
11.45)\end{array}$ & 0.009 \\
\hline \multirow[t]{2}{*}{ Poor job prospect } & $\begin{array}{l}\text { Not } \\
\text { significant }\end{array}$ & 0 & 1 & & 0 & 1 & \\
\hline & $\begin{array}{l}\text { Significant } \\
\text { Stressor }\end{array}$ & 1.76 & $\begin{array}{l}5.81(1.76, \\
19.17)\end{array}$ & 0.004 & 1.73 & $\begin{array}{l}5.65(1.27 \\
25.07)\end{array}$ & 0.023 \\
\hline
\end{tabular}

As compared to the male caretaker, the female caretaker has the higher odds of having personal burnout $(\mathrm{OR}=2.55,95 \% \mathrm{Cl}=1.01,6.47, \mathrm{p}=$ 0.049), when adjusted to number of house occupant, child's type of illness, family stressor, performance pressure stressor and poor job prospect stressor. As compared to those who had four or less occupants in the house, the odd ratio of having personal burnout among those who had seven or more occupants higher (OR $=4.15$, $95 \% \mathrm{Cl}=1.77,9.72, \mathrm{p}=0.001$ ) when adjusted to the caretaker's gender, child's type of illness, family stressor, performance pressure stressor and poor job prospect stressor. Caretakers of children with cerebral palsy have a higher odds of experiencing personal burnout, as compared to those taking care of children with epilepsy (OR = $2.89,95 \% \mathrm{Cl}=1.25,6.68, \mathrm{p}=0.013)$, and this was also higher for those taking care of children with genetic illness $(\mathrm{OR}=6.96,95 \% \mathrm{Cl}=1.42,34.03, \mathrm{p}$ $=0.017$ ). 


\section{Discussion}

The mean age of caretakers in this study was 38.12 years old. Majority of them were female, Malay ethnicity, Muslim, mothers, married and healthy. Mean age of children in this study was 7.19 years old, and most of them were male, had 3 siblings and already had the illness for more than 5 years. Another study done in parents of children with type 1 diabetes and inflammatory bowel disease also showed higher response rate in mothers as compared to fathers and included children with mean duration of disease of 5 years [24]. Parenting was often regarded as important domain in mothers as compared to fathers [13]. This can partly explain the higher participation of mothers in the current study. Some fathers refused to participate in this study, claiming that care giving was mainly done by mothers. The other possible explanation was most of the time fathers were at work. Therefore, care taking was left for the mothers. Unfortunately, this data was not captured during the study period.

The current study included caretakers of children with chronic neurological illnesses. Only 53\% of children were registered as people with disability. According to Laws of Malaysia (Persons with Disabilities Act 2008), registration for people with disabilities in Malaysia was voluntary. However, it will be mandatory for entry into early intervention program or Integrated Special Education Program later. Privileges may not be well-informed to parents. Therefore, it was deemed unnecessary to register. Some parents may still be in the state of denial regarding their child's diagnosis and refused to register. Children with epilepsy wouldn't qualify for disability card if the condition did not result in neurological sequelae or delayed development.

There were no associations between children's gender, age, duration of illness and caretaker's marital status and burnout. This was consistent with previous study that showed no association between demographic factors, parent's education and marital status with burnout [24].

Among all caretakers, the most common burnout was personal burnout. Those taking care of children with genetic illness, cerebral palsy and autism had a higher prevalence of personal burnout compared to overall participants. A study done in Iran on caregiver burden of children with chronic diseases also found that maximum care giving burden was observed in those caring for children with cerebral palsy [25]. It was also noted in the study that prolonged duration of disease were associated with higher caregiver burden, as well as poorer quality of life and mental health of their parents [25]. Prevalence of personal burnout in caretakers of children with genetic illness was as high as $60 \%$ in the current study. However, only 10 caretakers had children with genetic illnesses (including Neurofibromatosis Type 1, Tuberous sclerosis, Joubert syndrome and Dandy Walker). Therefore, further study with larger samples was needed to find the true effect of this association. When looking at chronicity of disease, this result was consistent with a study done in Sweden that showed parents of chronically ill children with type 1 diabetes and inflammatory bowel disease had significantly more burnout symptoms than parents of healthy children [13].

The highest prevalence of client-related burnout in this study was among caretakers of children with genetic illness, followed by autism and cerebral palsy. Dealing with different types of chronic neurological illness imposed different levels of caregiver burden [26] leading to varying degree of stress. Another study done in 2014 showed mothers of children affected by Neurofibromatosis type 1 reported higher mean parenting stress than the mothers of typically developing children [27]. It was noted in the current study that those caring for more than one child were more likely to have client-related burnout, caring for 3 children increased the likelihood of having client-related burnout by 5 times. In the current study, as compared to those who had four or less occupants in the house, the likelihood of having client-related burnout among those who had five or six occupants was 5.69 times higher. This was consistent with other studies that showed good social support provided by extended families decreased caregiver burden, responsibilities and stressors $[25,28,29]$.

The highest prevalence of work-related burnout was among the caretakers of children with metabolic illness, followed by those with intellectual disability and autism, while none of the caretakers of children with acquired neurological illness and genetic illness had work- 
related burnout. However, the overall prevalence of work-related burnout in this study was very low, $4.6 \%$. This was lower than average prevalence of $14 \%$ parental burnout in the context of typically developing children [30, 31]. Questions on work-related burnout were answered in relation to a task of caring for their own children. Due to this interpretation of 'work', sub-dimensions of work-related burnout and client-related burnout measured similar domain of caring for their own child. Questions in subdimension of work-related burnout were asking regarding caretaker's perception of parental work. In sub-dimension of client-related burnout, questions were more focusing on their interaction with their child.

It was interesting to find that only $4.6 \%$ of caretakers were having work-related burnout as compared to $17.5 \%$ experiencing client-related burnout. Majority of participants were Malays. Most Malays were Muslims who were taught to accept their sick child or disabled child as part of their faith and a way to make a person or family stronger [31]. Religion plays an important role as coping mechanism. A study done on burnout of parents of school age children with cancer found that educational-spiritual intervention was effective on reduction of burnout [32]. On the other hand, a study conducted in 2013 on caregivers of children with cerebral palsy showed having a disabled child was causing interference with quality of life for caregivers and higher burnout levels compared to control group. The same study also showed functional limitations of children were correlated with poorer caretakers' quality of life, mental health and burnout [11].

In the $11^{\text {th }}$ Revision of the International Classification of Diseases (ICD-11), burnout was included as an occupational phenomenon. It was defined as a syndrome conceptualised as resulting from chronic workplace stress that has not been managed successfully [33]. This was characterised by 3 dimensions, feelings of energy depletion or exhaustion; increased mental distance from one's job, or feelings of negativism or cynicism related to one's job; and reduced professional efficacy [33]. In the current study, caretaker burnout was indirectly measuring parental burnout. Parental burnout was a relatively new concept [8]. It was unclear whether current available tools were accurate measures of parental burnout [34]. Parental burnout has a larger association with couples' conflicts and partner estrangement, escape and suicidal ideation, child neglect and child violence [7].

Burnout experience had been postulated to occur following interaction between multiple sources of stressors that were uncompensated over a period of time. Parental burnout resulted from chronic imbalance of risks over resources available in the parenting domain [8]. In the current study, the most common stressors were performance pressure, work-family conflict and poor job prospects. Multiple logistic regression analyses showed that family stressor, types of child's neurological illness and number of household occupants were associated with parental burnout. GSQ family domain consisted of questions asking about family dynamics [18].

In the current study, caretakers with significant family stressors were 24 times more likely to have personal burnout, 12 times more likely to have total burnout and 17 times more likely to have client-related burnout. This was consistent with a study involving 372 French parents where it showed having many children at home were risk factor for both emotional distancing and loss of sense of achievement [35]. Another study showed severity of functional limitation of children with cerebral palsy had a significant association with mental health and wellbeing of caregivers [11].

Findings in this study emphasised the importance of exploring social circumstances surrounding children and their caretaker. Caretakers with significant family stressors need to be identified and referred for further assistance and respite care because they were at higher risk of experiencing burnout.

\section{Limitations}

This study had several limitations. This was a cross-sectional study done at a single centre, in the capital of Kelantan. Most of the participants were Malays. It might not be generalised to whole multi-cultural Kelantan population. It was unable to determine cause and effect relationships with main findings were only possible associations. This study did not examine protective factors as well as consequences of caretaker burnout. Furthermore, CBI-M and GSQ were adapted from 
the job-related constructs. Some of the questions in $\mathrm{CBI}-\mathrm{M}$ were redundant when participants were asked to consider 'work' as taking care of their children and 'client' also was referring to their child. Questions in most domains of GSQ were related to working with peers or superior. Therefore, some of these questions were somewhat non-applicable to this current study.

\section{Conclusion}

This study showed that caretakers of children with chronic neurological illness had higher levels of burnout than those caring for normally developing children. Prevalence of total burnout among the caretakers of children with chronic neurological illness was low, but personal burnout was prominent. Associated factors for personal burnout were being a female, having 5-6 occupants in the house and caring for children with cerebral palsy or genetic disorder. Significant stressors identified were family stressors, performance pressure and poor job prospect.

\section{Acknowledgement}

Financial support for this study was received from the Universiti Sains Malaysia Grant (Grant ID 1001/PPSP/8012292). The authors would like to thank The Director General of Ministry of Health Malaysia for the opportunity to use Hospital Raja Perempuan Zainab II as a research site. Special thanks to Pediatric clinic Hospital Raja Perempuan Zainab II, Medical Research Ethic Committee Ministry of Health Malaysia, Research Ethics Committee of Universiti Sains Malaysia and our research assistants.

\section{References}

[1.] Schulz R, Sherwood PR. Physical and mental health effects of family caregiving. The American Journal of Nursing. 2008;108(9 Suppl):23-7.

[2.] Maslach C, Leiter MP. Understanding the burnout experience: recent research and its implications for psychiatry. World Psychiatry. 2016;15(2):103-11.

[3.] C.J. wijesinghe $\mathrm{CGH}$, P.Fonseka. prevalence and predictors of psychological problems among principal caregivers of children with cerebral palsy in Galle, Sri Lanka. Journal of The College Community Physicians of Sri Lanka. 2013.
[4.] Hubert S, Aujoulat I. Parental Burnout: When Exhausted Mothers Open Up. Frontiers in Psychology. 2018;9(1021).

[5.] Mikolajczak M, Gross J, Roskam I. Parental Burnout: What Is It, and Why Does It Matter? Clinical Psychological Science. 2019.

[6.] Mikolajczak M, Roskam I. A Theoretical and Clinical Framework for Parental Burnout: The Balance Between Risks and Resources (BR(2)). Frontiers in psychology. 2018;9:886-.

[7.] Mikolajczak M, Brianda ME, Avalosse $H$, Roskam I. Consequences of parental burnout: Its specific effect on child neglect and violence. Child abuse \& neglect. 2018;80:13445.

[8.] Mikolajczak M, Raes M-E, Avalosse H, Roskam I. Exhausted parents: Sociodemographic, child-related, parent-related, parenting and family-functioning correlates of parental burnout. Journal of Child and Family Studies. 2018;27(2):602-14.

[9.] Emerson L-M, Bögels S. A Systemic Approach to Pediatric Chronic Health Conditions: Why We Need to Address Parental Stress. Journal of Child and Family Studies. 2017;26(9):23478.

[10.] Sullivan AB, Miller D. Who is Taking Care of the Caregiver? Journal of Patient Experience. 2015;2(1):7-12.

[11.] Basaran A, Karadavut K, Uneri O, Balbaloğlu Ö, Atasoy N. The effect of having a children with cerebral palsy on quality of life, burnout, depression and anxiety scores: A comparative study. European journal of physical and rehabilitation medicine. 2013;49.

[12.] Goudie A, Narcisse M-R, Hall DE, Kuo DZ. Financial and psychological stressors associated with caring for children with disability. Families, System and Health: The Journal of collaborative family healthcare. 2014;32(3):280-90.

[13.] Lindström C, Åman J, Norberg A. Increased prevalence of burnout symptoms in parents of chronically ill children. Acta Paediatrica. 2010;99(3):427-32.

[14.] Shobana M SC. Comparative study on attitudes and psychological problems of mothers towards their children with developmental disability. East Asian Archives Psychiatry. 2014;24(1):16-22.

[15.] Norizan A, Shamsuddin K. Predictors of parenting stress among Malaysian mothers of 
children with Down syndrome. Journal of intellectual disability research : JIDR. 2010;54:992-1003.

[16.] Andrew Chin RW, Chua YY, Chu MN, Mahadi NF, Wong MS, Yusoff MSB, et al. Investigating validity evidence of the Malay translation of the Copenhagen Burnout Inventory. Journal of Taibah University Medical Sciences. 2018;13(1):1-9.

[17.] Enderlein G. Daniel, Wayne W.: Biostatistics A Foundations for Analysis in the Health Sciences. Wiley \& Sons, New YorkChichester-Brisbane-Toronto-Singapore, 6th ed. 1995, 780 S., £58.-, ISBN 0-47158852-0 (cloth). Biometrical Journal. 1995;37(6):744-.

[18.] Yusoff MSB, Esa A. The Reliability and Validity of the General Stressor Questionnaire (GSQ) among House Officers. International Medical Journal (1994). 2011;18:179-82.

[19.] Nelson JA, O'Brien M, Blankson AN, Calkins SD, Keane SP. Family stress and parental responses to children's negative emotions: tests of the spillover, crossover, and compensatory hypotheses. Journal of Family Psychology. 2009;23(5):671-9.

[20.] Brough P, O'Driscoll M. Work-family conflict and stress. Research Companion to Organizational Health Psychology. 2005.

[21.] Kristensen $T$, Borritz $M$, Villadsen $E$, Christensen K. The Copenhagen Burnout Inventory: A new tool for the assessment of burnout. Work and Stress - WORK STRESS. 2005;19:192-207.

[22.] Mikolajczak M, Gross J, Roskam I. Parental Burnout: What Is It, and Why Does It Matter? Clinical Psychological Science. 2019;7.

[23.] Subramaniam S. A study of burnout in caretaker of children with cancer[master's thesis]. Universiti Sains Malaysia. 2018.

[24.] Lindström C, Åman J, Norberg AL. Parental burnout in relation to sociodemographic, psychosocial and personality factors as well as disease duration and glycaemic control in children with Type 1 diabetes mellitus. Acta Paediatrica. 2011;100(7):1011-7.

[25.] Piran P, Khademi Z, Tayari N, Mansouri N. Caregiving burden of children with chronic diseases. Electron Physician. 2017;9(9):53807.
[26.] Wijesinghe CJ, Cunningham N, Fonseka $P$, Hewage CG, Ostbye T. Factors associated with caregiver burden among caregivers of children with cerebral palsy in Sri Lanka. Asia Pac Journal of Public Health. 2015;27(1):8595.

[27.] Esposito M, Marotta R, Roccella M, Gallai B, Parisi L, Lavano SM, et al. Pediatric neurofibromatosis 1 and parental stress: a multicenter study. Neuropsychiatric Disease Treatment. 2014;10:141-6.

[28.] Raina $P$, O'Donnell $M$, Rosenbaum $P$, Brehaut J, Walter S, Russell D, et al. The Health and Well-Being of Caregivers of Children With Cerebral Palsy. Pediatrics. 2005;115:e626-36.

[29.] Hsieh R-L, Hsueh Y-M, Huang $H-Y$, Lin $M-I$, Tseng W-C, Lee W-C. Quality of life and impact of children with unclassified developmental delays. Journal of Paediatrics and Child Health. 2013;49.

[30.] Van Bakel HJA, Van Engen ML, Peters P. Validity of the Parental Burnout Inventory Among Dutch Employees. Frontiers in Psychology. 2018;9(697).

[31.] Isa SNI, Ishak I, Rahman AA, Saat NZM, Din NC, Lubis SH, et al. Perceived Stress and Coping Styles among Malay Caregivers of Children with Learning Disabilities in Kelantan. Malaysian Journal of Medical Sciences. 2017;24(1):81-93.

[32.] Beheshtipour N, Nasirpour P, Yektatalab S, Karimi M, Zare N. The Effect of EducationalSpiritual Intervention on The Burnout of The Parents of School Age Children with Cancer: A Randomized Controlled Clinical Trial. International Journal of Community Based Nursing and Midwifery. 2016;4(1):90-7.

[33.] Organisation WH. International Classification of Diseases for mortality and morbidity statistics (11th revision). WHO. 2018.

[34.] Roskam I, Brianda M-E, Mikolajczak M. A Step Forward in the Conceptualization and Measurement of Parental Burnout: The Parental Burnout Assessment (PBA). Frontiers in Psychology. 2018;9(758).

[35.] Vigouroux SL, Scola C. Differences in Parental Burnout: Influence of Demographic Factors and Personality of Parents and Children. Frontiers in Psychology. 2018;9(887). 